\title{
Structural response of interlocking composite masonry slab.
}

\begin{abstract}
This study introduces a semi-fabricated composite floor slab system that consists of a precast inverted ribbed ferrocement panel interlocked in situ with a brick-rib layer to form a composite slab. The effectiveness of the interlocking mechanism of the composite slab was investigated under separate shear and flexural loadings. Ten composite slab specimens having different shear connectivity between the two layers were cast and tested under pure shear loading (push-off test). Six further slab specimens were cast and tested under two line loadings to explore the structural response of the composite slab system under flexural loading. The flexural tests focused on the effect of different brick layouts and orientation and thus different numbers of interlocking ribs in longitudinal and transverse directions on the overall structural response of the composite slab. The results of push-off tests indicate that the proposed interlocking system is as effective as using steel truss shear connectors in composite slabs. The flexural test results in terms of load-deflection, crack pattern, ductility and failure loads indicate that the response of the composite slab to flexural loading is satisfactory for use as a structural floor slab.
\end{abstract}

Keyword: Buildings; Composite structures; Failures; Structures \& design 